\title{
1,4-Hydroquinone is a Hydrogen Reservoir for Fuel Cells and Recyclable via Photocatalytic Water Splitting
}

\author{
Thorsten Wilke, Michael Schneider, Karl Kleinermanns* \\ Institute of Physical Chemistry, Heinrich-Heine-University, Duesseldorf, Germany \\ Email: *kleinermanns@uni-duesseldorf.de \\ Received February 14, 2013; revised March 20, 2013; accepted April 20, 2013
}

Copyright (C) 2013 Thorsten Wilke et al. This is an open access article distributed under the Creative Commons Attribution License, which permits unrestricted use, distribution, and reproduction in any medium, provided the original work is properly cited.

\begin{abstract}
Photocatalytic splitting of water was carried out in a two-phase system. Nanocrystalline titanium dioxide was used as photocatalyst and potassium hexacyanoferrate(III)/(II) as electron transporter. Generated hydrogen was chemically stored by use of a 1,4-benzoquinone/1,4-hydroquinone system, which was used as a recyclable fuel in a commercialised direct methanol fuel cell (DMFC). The electrical output of the cell was about half compared to methanol. The conversion process for water splitting and recombination in a fuel cell was monitored by UV-Vis spectroscopy and compared to a simulated spectrum. Products of side reactions, which lead to a decrease of the overall efficiency, were identified based on UV-Vis investigations. A proof of principle for the use of quinoide systems as a recyclable hydrogen storage system in a photocatalytic water splitting and fuel cell cyclic process was given.
\end{abstract}

Keywords: Fuel Cell; DMFC; Water Splitting; Recyclable Fue; $\mathrm{TiO}_{2}$; Chemical Hydrogen Storage; Quinones

\section{Introduction}

By the year 2050 the total energy consumption is expected to double, as the world's population is steadily increasing. The fossil fuels are not able to meet this energy demand in the long term. Therefore, renewable energy resources will come more sharply into focus. The most promising alternative is solar light, because the amount of energy that arrives on earth every hour from the sun is greater than the amount that is required by the entire humanity in one year [1]. Yet, there is no practical way to transform and store this huge amount of energy efficiently, because the widely used silicon solar cells are of limited use due to their high production costs. Therefore, it is necessary to look for less expensive and in sufficient quantities available alternatives to high-purity silicon. Storage of solar energy is possible for example by batteries and capacitors, but, compared to chemical bonds, these storage systems feature a low energy density. In this regard hydrogen is a good energy reservoir. It can be used as fuel for vehicles or can be converted into electrical energy by the use of fuel cells. The generation of hydrogen by electrolysis requires electrical energy, which could be obtained by use of solar cells, but the effectiveness is just approximately $8 \%$ for large-scale facilities [2]. Thus, direct photolytic water splitting by the use of suit-

${ }^{*}$ Corresponding author. able and inexpensive nanocrystalline semiconductors would be a promising alternative. Here the water is split with high efficiency by solar light $[1,3,4]$.

The semiconductor titanium dioxide has a band gap of about $3.1 \mathrm{eV}$ and its conduction band potential is high enough for water splitting [5]. By absorption of photons electrons can be promoted to the excited state and electron-hole pairs $\left(\mathrm{e}^{-}+\mathrm{h}^{+}\right)$are generated, which diffuse separately on the surface of the $\mathrm{TiO}_{2}$ particles:

$$
\mathrm{TiO}_{2}+h v \rightarrow \mathrm{e}^{-}+\mathrm{h}^{+}
$$

The formed holes in the valence band are able to oxidize molecules, for example water:

$$
\mathrm{H}_{2} \mathrm{O}+2 \mathrm{~h}^{+} \rightarrow \frac{1}{2} \mathrm{O}_{2}+2 \mathrm{H}^{+}
$$

The electrons in the conduction band can reduce $\mathrm{H}^{+}$to hydrogen as the reduction potential of $\mathrm{TiO}_{2}$ is sufficiently negative $(-0.65 \mathrm{~V}[6])$ :

$$
2 \mathrm{H}^{+}+2 \mathrm{e}^{-} \rightarrow \mathrm{H}_{2}
$$

For water splitting by $\mathrm{TiO}_{2}$ we finally obtain the following overall reaction [7]:

$$
\mathrm{H}_{2} \mathrm{O}+2 h v \rightarrow \frac{1}{2} \mathrm{O}_{2}+\mathrm{H}_{2}
$$

Depending on the particle size, $\mathrm{TiO}_{2}$ nanoparticles (NPs) absorb at wavelengths smaller than $350-380 \mathrm{~nm}$ 
[8]. Larger particles show smaller band gaps, thus the absorption is red-shifted.

For an efficient and safe chemical storage of the generated hydrogen quinoid systems are suitable. They mimic natural processes, e.g., photosynthesis, which also use quinoid systems like plastoquinone for hydrogen transfer [7].

Substituted quinoides like 2,3-dichloro-5,6-dicyano-1,4benzoquinone (DDQ) are known from literature as good hydrogen acceptors [9] and were already investigated by our group in the past [4]. 1,4-benzoquinone is less efficient compared to substituted quinoides, but in contrary to DDQ it can be converted in a direct methanol fuel cell (DMFC), because of its relatively good resistance to water. Benzoquinone and hydroquinone are well distinguishable by UV-VIS spectroscopy allowing rather easy quantitative analysis.

Our group presented in 2012 a photocatalytic reaction system for splitting water by use of semiconductor nanoparticles [4], which is a further development of an experimental setup introduced by Matsumura et al. in 1999 [9]. The experimental setup consists of a two-phase system. The photocatalytic water splitting takes place in the aqueous phase containing the photocatalyst and the electron transporter. It is covered with a solution of quinone in n-butyronitrile, which forms the organic layer and serves as hydrogen storage system.

Hydroquinone is formed by reduction of benzoquinone and acceptance of two protons.

$$
\mathrm{BQ}+2 \mathrm{e}^{-}+2 \mathrm{H}^{+} \rightarrow \mathrm{HQ}
$$

Benzoquinone and hydroquinone form quinhydrone complexes [BQ·HQ].

$$
\mathrm{BQ}+\mathrm{HQ} \rightarrow[\mathrm{BQ} \cdot \mathrm{HQ}]
$$

Quinhydrone is a dark green 1:1 charge-transfer, which is moderately soluble in n-butyronitrile. Dissolved quinhydrone undergoes a consecutive reduction to hydroquinone.

$$
[\mathrm{BQ} \cdot \mathrm{HQ}]+2 \mathrm{e}^{-}+2 \mathrm{H}^{+} \rightarrow 2 \mathrm{HQ}
$$

In this paper we show that quinones can be used as fuel for fuel cells. Hydroquinone is converted to benzoquinone in an air-breathing fuel cell normally used with methanol. Benzoquinone is converted back to hydroquinone by photocatalytic water splitting. Commercialised direct methanol fuel cells (DMFC) consist of a polymer electrolyte ion exchange membrane embedded between the anode and the cathode. Both electrodes are composed of three layers: a catalytic, diffusion and a backing layer, mostly based on Pt or Pt Ru as catalyst. For a successful transport of oxygen to the surface of the catalyst, a mixture of carbon and polytetrafluoroethylene is used as diffusion layer [10]. In air-breathing DMFCs atmospheric oxygen is used without active blowing components by diffusion through open holes of the cathode [11]. The following platinum catalysed reactions take place [12-14] anode:

$$
\mathrm{CH}_{3} \mathrm{OH}+\mathrm{H}_{2} \mathrm{O} \rightarrow \mathrm{CO}_{2}+6 \mathrm{H}^{+}+6 \mathrm{e}^{-} \quad \mathrm{U}^{0}=0.043 \mathrm{~V}(8) ;
$$

cathode:

$$
6 \mathrm{H}^{+}+6 \mathrm{e}^{-}+1.5 \mathrm{O}_{2} \rightarrow 3 \mathrm{H}_{2} \mathrm{O} \quad \mathrm{U}^{0}=1.229 \mathrm{~V}(9)
$$

overall reaction:

$$
\mathrm{CH}_{3} \mathrm{OH}+1.5 \mathrm{O}_{2} \rightarrow \mathrm{CO}_{2}+2 \mathrm{H}_{2} \mathrm{O} \quad \mathrm{U}^{0}=1.186 \mathrm{~V}(10) \text {. }
$$

Under real conditions the open circuit voltage is always lower than the theoretical value, because of overpotential effects at both electrodes.

The electrooxidation of hydroquinone can be described in similar way [14]

anode:

$$
2 \mathrm{HQ} \rightarrow 2 \mathrm{BQ}+4 \mathrm{H}^{+}+4 \mathrm{e}^{-} \quad \mathrm{U}^{0}=0.699 \mathrm{~V}(11)
$$

cathode:

$$
4 \mathrm{H}^{+}+4 \mathrm{e}^{-}+\mathrm{O}_{2} \rightarrow 2 \mathrm{H}_{2} \mathrm{O} \quad \mathrm{U}^{0}=1.229 \mathrm{~V}(12) ;
$$

overall reaction:

$$
\mathrm{HQ}+0.5 \mathrm{O}_{2} \rightarrow \mathrm{BQ}+\mathrm{H}_{2} \mathrm{O} \quad \mathrm{U}^{0}=0.530 \mathrm{~V}(13) \text {. }
$$

Due to overpotential effects the observed open circuit voltage is lower than the theoretical value.

\section{Experiments}

Titanium nanopowder (Aerosil $\mathrm{TiO}_{2}$ P-25, Evonik), 1,4-benzoquinone $(99.5 \%$, Aldrich), potassium hexacyanoferrate(III) (99\%, Aldrich), n-butyronitrile (purum, $\geq 99.0 \%$, Fluka) and 1,4-hydroquinone $(\geq 99 \%$, Aldrich) were used without purification or other treatment.

\subsection{Photocatalytic Water Splitting}

The water splitting experiments were carried out in a quartz cuvette of $45 \times 12.5 \times 12.5 \mathrm{~mm}^{3}$ size. $30 \mathrm{mg} \mathrm{\textrm {TiO } _ { 2 }}$ nanopowder was dispersed in $16 \mathrm{~mL}$ of an aqueous potassium hexacyanoferrate(III) solution (8.0 mM). $2.29 \mathrm{ml}$ of the dispersion was placed in the cuvette and was carefully covered with $0.71 \mathrm{~mL}$ of a 1,4-benzoquinone solution in n-butyronitrile $(1.9 \mathrm{mM})$ to form the organic phase. In order to avoid an evaporation of the organic solvent, the cuvette was sealed with a PTFE plug. To avert heating of the reaction system during irradiation and to reduce diffusion of $\mathrm{BQ}$ into the aqueous phase, the vessel was cooled to $15^{\circ} \mathrm{C}$ by a water flushed aluminium block, connected to the cuvette by a heat-conductive paste.

The irradiation was carried out for 90 minutes by an $80 \mathrm{~W}$ mercury-vapor lamp (Oriel, Germany), which was mildly focused to give $100 \mathrm{~mW} / \mathrm{cm}^{2}$.

To prevent irradiation of the organic phase and photodegradation of BQ and $\mathrm{HQ}$ an aluminium mask of ade- 
quate size was used.

To exclude contributions to the spectra, which were not due to the process of water splitting, a reference solution of the organic phase was kept in the dark without contact to the aqueous phase during irradiation.

After $90 \mathrm{~min}$ of irradiation a sample of the organic phase was taken, diluted 1:25 with n-butyronitrile and analysed by UV-Vis spectroscopy.

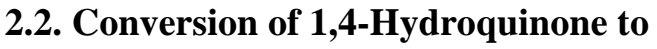 1,4-Benzoquinone in a Direct Methanol Fuel Cell (DMFC)}

The reaction was carried out in a F111 direct methanol fuel cell purchased from H-TEC Education GmbH with an electrode area of $4 \mathrm{~cm}^{2}$ and a maximal power output of $20 \mathrm{~mW}$. The cell was operated as an air-breathing fuel cell. Oxygen was obtained from the atmosphere by diffusion and convection.

To verify the given properties a $3 \%$ by weight solution of methanol ( $99.9 \%$, Aldrich) in water was used.

A 3\% by weight solution of 1,4-hydroquinone in water was poured into the cell until the electrode was soaked. The electrical output of the cell was recorded by a VC- 840 digital multimeter (Voltcraft, Germany) for 180 minutes reaction time.

Afterwards a sample of the reaction mixture was diluted with water and analysed by UV-Vis spectroscopy.

Furthermore, UV-Vis spectra of aqueous solutions of 1,4-benzoquinone and 1,4-hydroquinone in a 1:3 concentration value (BQ:HQ) were taken. A simulated UV-Vis spectrum of a 1:3 mixture of benzoquinone and hydroquinone in water was obtained by mathematical addition of the recorded spectra.

\subsection{Experimental Equipment}

To verify the given properties of the $\mathrm{TiO}_{2}$ nanopowder transmission electron microscopy (TEM) images were taken.

The particle size distribution was investigated by transmission electron microscopy (TEM) measurements, which were performed with a HITACHI TEM 7500 microscope equipped with a Mega View II camera (Soft Imaging System) at the Max-Planck institute for coal research (MPI Mülheim a.d. Ruhr).

The TEM image of the $\mathrm{TiO}_{2}$ nanoparticles is presented in Figure 1. An average particle size of $21 \mathrm{~nm}$ and a homogeneous size distribution have been found.

Optical absorption spectra of the organic phase were recorded by using a Cary 300 UV-VIS spectrophotometer operated at a resolution of $1 \mathrm{~nm}$.

\section{Results and Discussion}

Our experimental setup is shown in Figure 1. A solution of 1,4-benzoquinone in $\mathrm{n}$-butyronitrile forms the organic

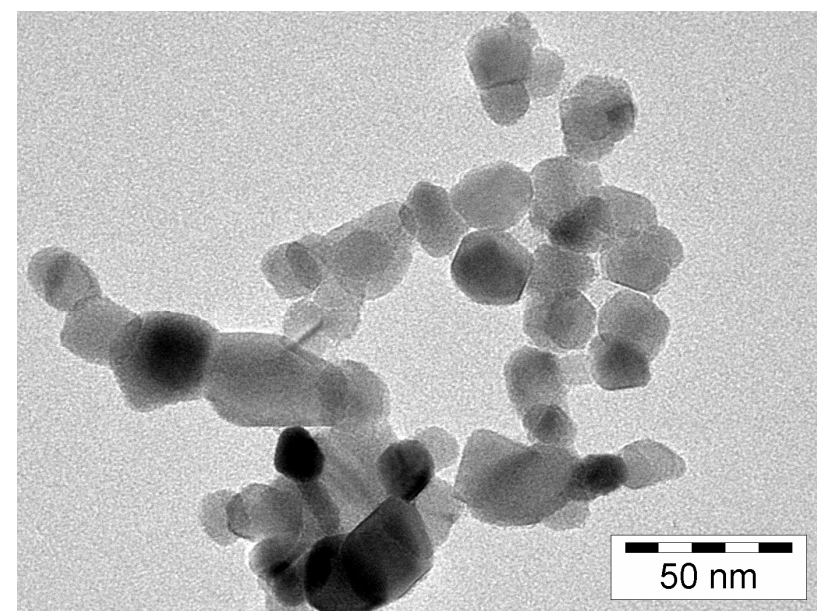

Figure 1. TEM image of $\mathrm{TiO}_{2}$ nanoparticles with an average size of $21 \mathrm{~nm}$ obtained from Evonik (Aerosil $\mathrm{TiO}_{2} \mathrm{P}-25$ ). It consists of a mixture of $80 \%$ anastase and $20 \%$ rutile with a specific surface area of approximately $50 \mathrm{~m}^{2} / \mathrm{g}$.

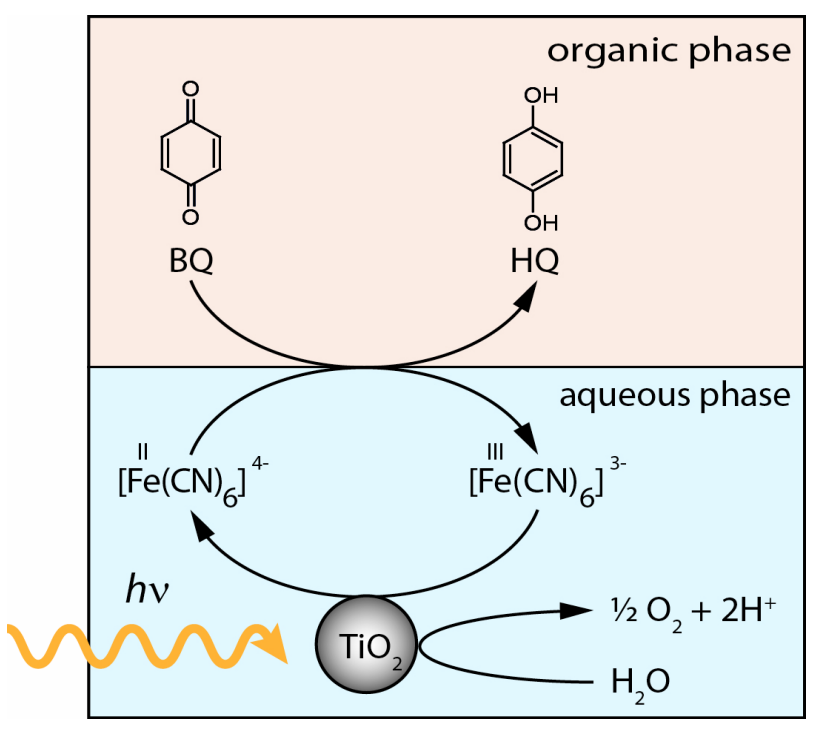

Figure 2. Experimental setup. The reaction is carried out in a two-phase system. Nanocrystalline $\mathrm{TiO}_{2}$ is used as photocatalyst and is suspended in a solution of $K_{3}\left[\mathrm{Fe}(\mathrm{CN})_{6}\right]$ in water, which forms the aqueous phase. It is covered with a layer of the organic phase, a solution of 1,4-benzoquinone (BQ) in n-butyronitrile [9]. The reaction cell is tempered by a water cooling block to approximately $15^{\circ} \mathrm{C}$ to reduce diffusion of BQ into the aqueous phase. The aqueous phase is irradiated by a Hg lamp, which is mildly focused to give 100 $\mathrm{mW} / \mathrm{cm}^{2}$. Aluminium foil prevents irradiation of the organic phase.

layer and is located above the aqueous phase, in which the water splitting takes place. A $\left[\mathrm{Fe}^{+\mathrm{HI}}(\mathrm{CN})_{6}\right]^{4-}-\left[\mathrm{Fe}^{+\mathrm{III}}(\mathrm{CN})_{6}\right]^{3-}$ redox system transports the electrons between the two phases. The holes in the valence band of titanium dioxide oxidize water, while electrons excited to the conduction band reduce the $\left[\mathrm{Fe}^{+\mathrm{III}}(\mathrm{CN})_{6}\right]^{3-}-$ to $\left[\mathrm{Fe}^{+\mathrm{III}}(\mathrm{CN})_{6}\right]^{4-}$-ions. The reduced ferrocyanide ions transport electrons to the 
interface, where benzoquinone is subsequently reduced to semihydroquinone and hydroquinone by accepting electrons from $\left[\mathrm{Fe}^{+\mathrm{II}}(\mathrm{CN})_{6}\right]^{4-}$ and protons from water. Because of the spatial separation of reduction and oxidation processes in two different phases, electron-hole recombination can be minimized and the oxidation of hydroquinone by $\mathrm{TiO}_{2}$-holes can be prevented. The redox scheme in Figure $\mathbf{3}$ confirms the energetic feasibility of this approach.

Figure 4 shows the UV-Vis spectra of 1,4-benzoquinone and their suitability for quantitative analysis of the reduction process.

The result of the water splitting experiment is presented in Figure 5. There the UV-Vis spectrum of the diluted organic phase before and after 90 minutes irradiation with the unfiltered $\mathrm{Hg}$ lamp spectrum is shown. The strong absorption band at $244 \mathrm{~nm}$ can be assigned to benzoquinone. The absorption band at $296 \mathrm{~nm}$, which is much weaker because of different absorption coefficients (1,4-benzoquinone: $\varepsilon_{244 \mathrm{~nm}}=19204 \mathrm{~L} \cdot \mathrm{mol}^{-1} \cdot \mathrm{cm}^{-1}$; 1,4-hydroquinone: $\varepsilon_{244 \mathrm{~nm}}=3453 \mathrm{~L} \cdot \mathrm{mol}^{-1} \cdot \mathrm{cm}^{-1}$ ), can be assigned to hydroquinone. A magnification of the hydroquinone absorption band is presented in the inset.

After irradiation for 90 minutes the absorption band at $244 \mathrm{~nm}$ decreased by $32 \%$ due to the conversion of benzoquinone to hydroquinone and some side reactions, which lead to a loss of quinone. The oxidative polymerisation of benzoquinone in water $[15,16]$ at the interphase between organic and aqueous phase is the mostimportant side reaction: a small amount of quinone diffuses into the

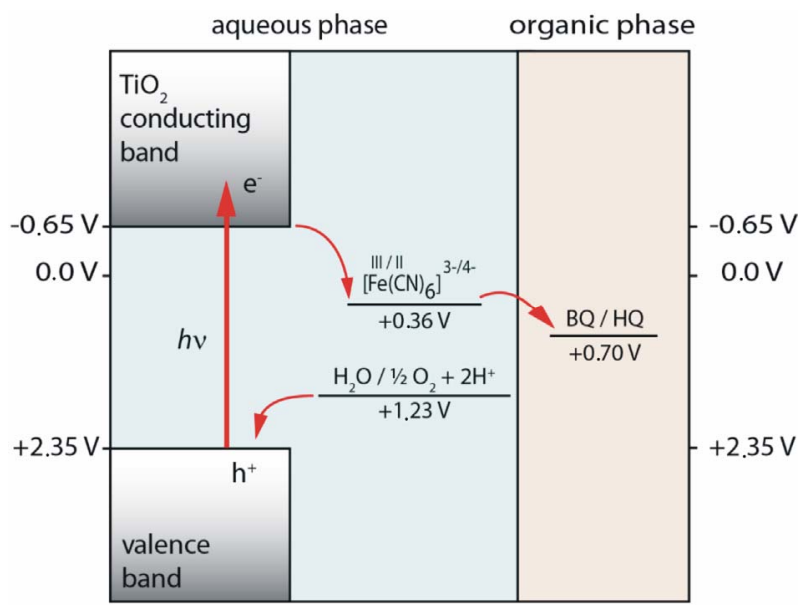

Figure 3. Energy scheme of the two-phase water splitting experiment. Redox potentials are given in Volts [V] against Standard Hydrogen Potential [SHE]. The working principle is based on excitation of $\mathrm{TiO}_{2}$. The excited electron $\left(\mathrm{e}^{-}\right)$is stored by reducing $\left[\mathrm{Fe}(\mathrm{CN})_{6}\right]^{--}$to $\left[\mathrm{Fe}(\mathrm{CN})_{6}\right]^{4-}$ and transported to the interphase by diffusion. The electron transporter is regenerated to $\left[\mathrm{Fe}(\mathrm{CN})_{6}\right]^{3-}$ by reducing $\mathrm{BQ}$. Holes $\left(h^{+}\right)$in the valence band are filled by oxidation of water leading to $\mathrm{O}_{2}$ and $\mathrm{H}^{+}$. HQ is formed at the interface by reaction of $\mathrm{H}^{+}$with the reduced $\mathrm{BQ}$.

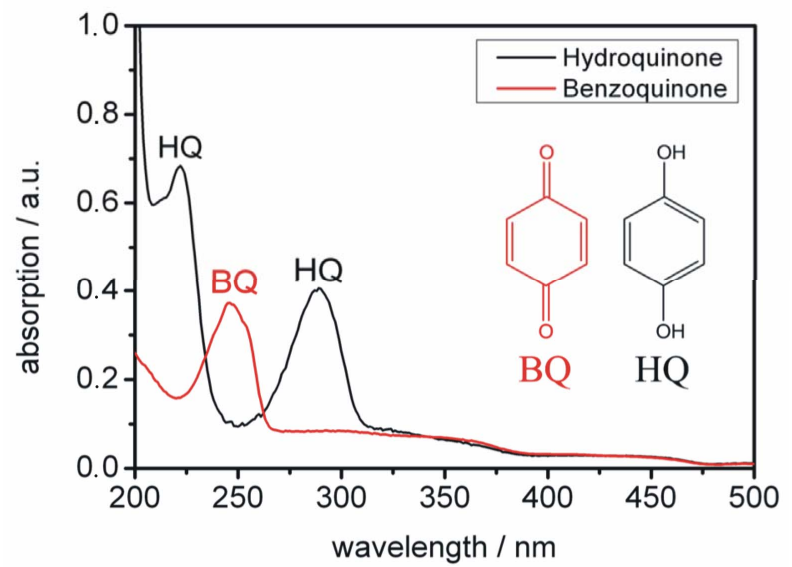

Figure 4. UV-Vis spectra of 1,4-benzoquinone (red) and 1,4-hydroquinone (black) measured in water in a 1:5 (BQ:HQ) concentration ratio. Benzoquinone shows strong absorption with a maximum at $244 \mathrm{~nm}$, while hydroquinone absorption is considerably weaker with maxima at $222 \mathrm{~nm}$ and $296 \mathrm{~nm}$. The spectra were obtained using a suprasil quartz cell with $1 \mathrm{~cm}$ path length and a double-beam UVVis spectrophotometer operated at a resolution of $1 \mathrm{~nm}$.

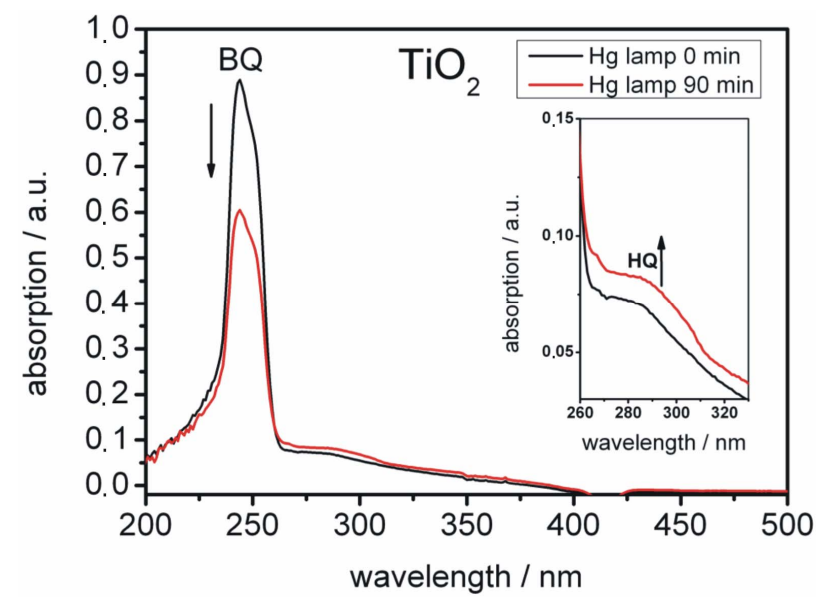

Figure 5. Water splitting by $\mathrm{TiO}_{2}$ as photocatalyst. Shown are the UV-Vis spectra of the organic phase before (black line) and after irradiation (red line) of the aqueous phase with an unfiltered $\mathrm{Hg}$ lamp spectrum for 90 minutes. The recorded strong absorption at $244 \mathrm{~nm}$ can be assigned to benzoquinone. It is decreasing while irradiation due to the conversion of benzoquinone to hydroquinone. Hydroquinone shows absorption at $296 \mathrm{~nm}$. Because of the different absorption coefficients the absorption is much weaker compared to benzoquinone. A magnification of the spectra is shown in the inset.

aqueous phase and undergoes condensation reactions leading to high-molecular species of humic acid type [16].

After 90 minutes of irradiation $37 \%$ of the consumed benzoquinone were converted to hydroquinone. Overall we achieved a total conversion rate of about $12 \%$. Compared to other quinoide systems like 2,3-dichloro- 
5,6-dicyano-1,4-benzoquinone (DDQ), which has been investigated by our group in the past [4], the unsubstituted p-benzoquinone shows a significantly lower conversion rate. Contrary to water insoluble 2,3-dichloro5,6-dicyano-1,4-hydroquinone (DDHQ) however, waterbased 1,4-hydroquinone can be converted in a common direct methanol fuel cell (DMFC) into 1,4-benzoquinone. In this way, it is possible to achieve a cyclic process of photocatalytic water splitting for storage of solar energy and a fuel cell to convert it into electric energy. An image of the fuel cell after hydroquinone conversion is presented in Figure 6. To verify the given data, a solution of $3 \%$ by weight of methanol in water was used. After 10 minutes reaction time an open circuit voltage of $500 \mathrm{mV}$ and an electrical output of $20 \mathrm{~mW}$ was observed. For the conversion of a $3 \%$ by weight solution of 1,4-hydroquinone in water an open circuit voltage of $300 \mathrm{mV}$ and an electrical output of $9 \mathrm{~mW}$ was observed. The reaction was carried out for 180 minutes under load. During operation hydroquinone is converted into benzoquinone.

Aside quinhydrone is formed (Equation (6)) and some oxidative polymerisation of benzoquinone occurs. Quinhydrone is only poorly soluble in water. Therefore, precipitation of quinhydrone leads to a loss of quinone. An increasing greenish-brown colouring of the reaction solution and a fine precipitation was observed, which is shown in Figure 5.

The UV-Vis spectrum of the reaction mixture after conversion for 180 minutes in the fuel cell is presented in Figure 7 (black line). Two recorded absorption bands at $222 \mathrm{~nm}$ and $296 \mathrm{~nm}$ can be assigned to unreacted hydroquinone. Only weak absorption of benzoquinone at 244 $\mathrm{nm}$ was not observed because of the overlap with the absorption band of hydroquinone and underlying broad absorption of quinhydrone and polymerised benzoquinone. A difference spectrum of experiment and simulation is presented in the inset of Figure 7.

The absorption of quinhydrone in water exhibits an absorption band at $420 \mathrm{~nm}$ [17], which can be found in the spectrum of the reaction solution as well. Condensation of benzoquinone leads to a wide variety of highmolecular products of humic acid type, which show a wide absorption in the range of $300 \mathrm{~nm}$ to $500 \mathrm{~nm}$ [16].

\section{Conclusion}

We presented an experimental setup for photocatalytic water splitting by nanocrystalline titanium dioxide and a chemical storage of the generated hydrogen by hydroquinone. The benzoquinone/hydroquinone system seems to be a good alternative to the formation of gaseous $\mathrm{H}_{2}$ as it is easy to handle and can be used as a fuel for fuel cells. This work is a proof of principle for the use of quinoide systems as a recyclable storage medium in a photocata-

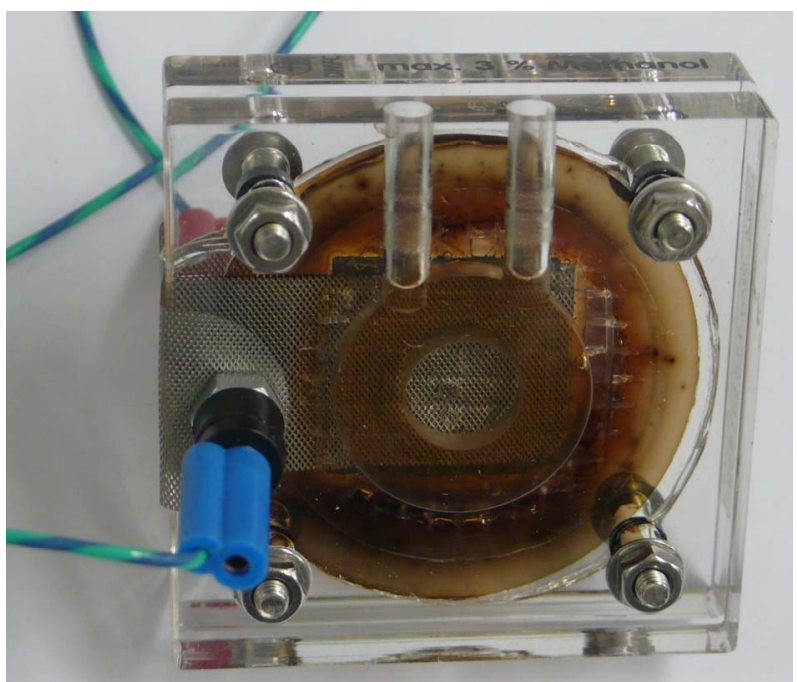

Figure 6. Image of the fuel cell after 180 minutes reaction time. An open circuit voltage of $300 \mathrm{mV}$, a short circuit current of $30 \mathrm{~mA}$ and corresponding electrical power of 9 $\mathrm{mW}$ was observed, which is nearly half the methanol fuel cell power. An increasing greenish-brown colouring of the reaction solution and a fine precipitate is observed with reaction time due to the formation of quinhydrone and oxidative polymerized benzoquinone [16].

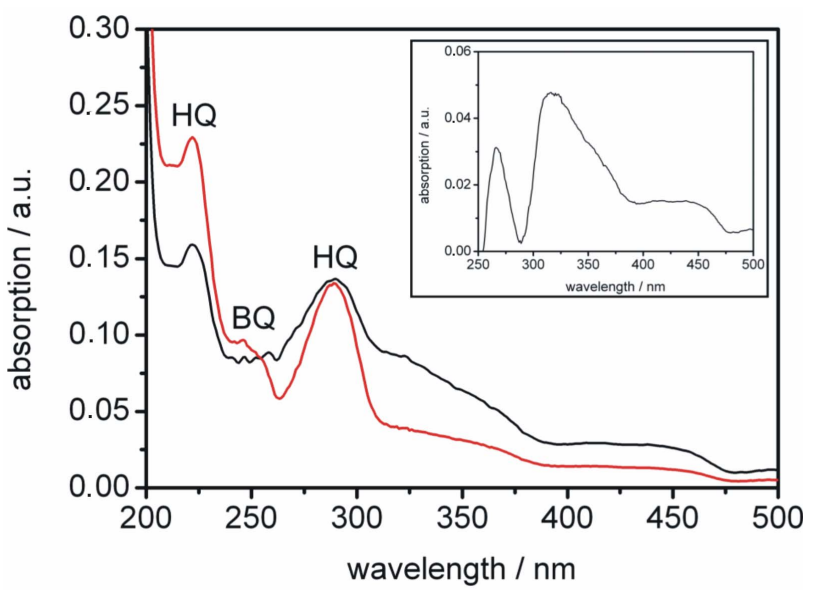

Figure 7. Conversion of hydroquinone in a common direct methanol fuel cell (DMFC). The black line shows the UVVis spectrum of an aqueous solution of hydroquinone (3\% in mass) after conversion in a DMFC for 3 hours. The achieved cell power was about half compared to methanol (3\% in mass) as fuel. The red line shows a simulated UVVis spectrum of a 1:3 mixture of benzoquinone and hydroquinone in water, achieved by addition of both spectra in a concentration ratio of 1:3 (BQ:HQ). The recorded absorption bands can be assigned to HQ (222 $\mathrm{nm}$ and $296 \mathrm{~nm})$ and BQ $(244 \mathrm{~nm})$. The inset shows the difference spectrum of the experimental and the simulated UV-Vis spectrum.

lytic water splitting and fuel cell cyclic process. Further work has to be directed to the development of quiniod derivates, which are water soluble and chemically resistant. 


\section{Acknowledgements}

The authors gratefully acknowledge Dr. Christian W. Lehmann and his group (Max-Planck Institut für Kohlenforschung, Mülheim/Ruhr) for the implementation of the TEM measurements.

\section{REFERENCES}

[1] R. Pike and P. Earis, "Powering the World with Sunlight," Energy \& Environmental Science, Vol. 3, No. 2, 2010, p. 173. doi:10.1039/b924940k

[2] N. Kelly, T. Gibson and D. Ouwerkerk, "Generation of High-Pressure Hydrogen for Fuel Cell Electric Vehicles Using Photovoltaic-Powered Water Electrolysis," International Journal of Hydrogen Energy, Vol. 36, No. 24, 2011, pp. 15803-15825. doi:10.1016/j.ijhydene.2011.08.058

[3] E. Durgun, S. Ciraci, W. Zhou and T. Yildirim, "Transition-Metal-Ethylene Complexes as High-Capacity Hydrogen-Storage Media," Physical Review Letters, Vol. 97, No. 22, 2006, pp. 1-4. doi:10.1103/PhysRevLett.97.226102

[4] T. Wilke, D. Schriker, J. Rolf and K. Kleinermanns, "Solar Water Splitting by Semiconductor Nanocomposites and Hydrogen Storage with Quinoid Systems," Open Journal of Physical Chemistry, Vol. 2, No. 4, 2012, pp. 195-203. doi:10.4236/ojpc.2012.24027

[5] M. Grätzel, "Photoelectrochemical Cells," Nature, Vol. 414, No. 6861, 2001, pp. 338-344. doi:10.1038/35104607

[6] A. Hagfeldt and M. Grätzel, "Light-Induced Redox Reactions in Nanocrystalline Systems," Chemical Reviews, Vol. 95, No. 1, 1995, pp. 49-68. doi:10.1021/cr00033a003

[7] M. Kaneko and I. Okura, "Photocatalysis-Science and Technology," Springer, Heidelberg, 2002.

[8] D. Ogermann, T. Wilke and K. Kleinermanns, "CdS $\mathrm{CSe}_{\mathrm{y}} /$ $\mathrm{TiO}_{2}$ Solar Cell Prepared with Sintered Mixture Deposition," Open Journal of Physical Chemistry, Vol. 2, No. 1, 2012, pp. 47-57. doi:10.4236/ojpc.2012.21007

[9] T. Ohno, K. Fujihara, K. Sarukawa, F. Tanigawa and M.
Matsumura, "Splitting of Water by Combining Two Photocatalytic Reactions through a Quinone Compound Dissolved in an Oil Phase," Zeitschrift für Physikalische Chemie, Vol. 213, No. 2,1999, pp. 165-174. doi:10.1524/zpch.1999.213.Part 2.165

[10] A. S. Aricò, V. Baglio and V. Antonucci, "Electrocatalysis of Direct Methanol Fuel Cells," Wiley-VCH, Weinheim, 2009.

[11] I. Chang, M. Lee, J. Du and S. W. Cha, "Characteristic Behaviors on Air-Breathing Direct Methanol Fuel Cells," International Journal of Precision Engineering and Manufacturing, Vol. 13, No. 7, 2012, pp. 1141-1144. doi:10.1007/s12541-012-0151-y

[12] H. Dohle, J. Mergel and D. Stolten, "Heat and Power Management of a Direct-Methanol-Fuel-Cell (DMFC) System," Journal of Power Sources, Vol. 111, No. 2, 2002, pp. 268-282. doi:10.1016/S0378-7753(02)00339-7

[13] A. S. Aricò, V. Antonucci and N. Giordano, "Methanol Oxidation on Carbon-Supported Platinum-Tin Electrodes in Sulfuric Acid," Journal of Power Sources, Vol. 50, No. 3, 1994, pp. 295-309. doi:10.1016/0378-7753(94)01908-8

[14] D. R. Lide and W. M. Haynes, "CRC Hanbook of Chemistry and Physics," Taylor \& Francis, London, 2009.

[15] L. L. Houk, S. K. Johnson, J. Feng, R. S. Houk and D. C. Johnson, "Electrochemical Incineration of Benzoquinone in Aqueous Media Using a Quaternary Metal Oxide Electrode in the Absence of a Soluble Supporting Electrolyte," Journal of Applied Electrochemistry, Vol. 28, No. 11, 1998, pp. 1167-1177. doi:10.1023/A:1003439727317

[16] F. Cataldo, "On the Structure of Macromolecules Obtained by Oxidative Polymerization of Polyhydroxyphenols and Quinones," Polymer International, Vol. 46, No. 4, 1998, pp. 263-268. doi:10.1002/(SICI)1097-0126(199808)46:4<263::AID-PI 983>3.0.CO;2-0

[17] K. K. Kalninsh and E. F. Panarin, "Catalytic Hydrogen Transfer in Donor-Acceptor Complexes," Doklady Chemistry, Vol. 437, No. 2, 2011, pp. 82-86. doi:10.1134/S0012500811040021 